\title{
Utility of intravenous indocyanine green injection in discovering stenosed hepatico- jejunal anastomoses following pancreaticoduodenectomy during ERCP
}

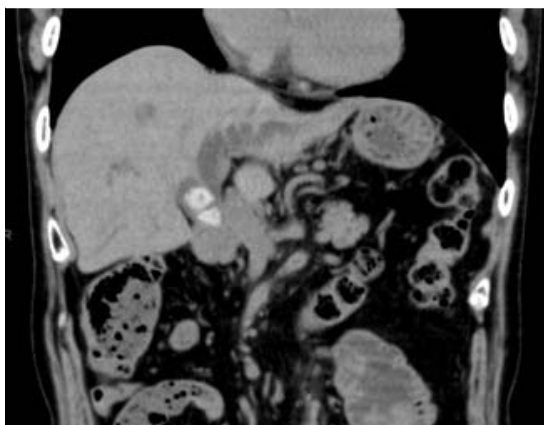

Fig. 1 Computed tomography demonstrated bile duct stones and a dilated intrahepatic bile duct.

Indocyanine green (ICG) is a green-colored dye that is taken up by hepatic cells when intravenously administered, does not undergo metabolic processes such as conjugation, and is excreted unchanged in the bile [1]. We speculated that ICG could be useful in identifying hepaticojejunal anastomoses, as ICG changes the bile color from yellow to green.

A 72-year-old man underwent pyloruspreserving pancreaticoduodenectomy with modified Child's method in 2011. He subsequently twice developed cholangitis due to hepaticojejunal anastomotic stenosis and bile duct stones, and underwent double-balloon endoscopybased endoscopic retrograde cholangiopancreatography (ERCP) at different medical facilities; however, the anastomosis could not be identified and followup observations were made. There were no incidents following this; however, in August 2019, the patient had cholangitis and was referred to our department.

Computed tomography demonstrated bile duct stones and a dilated intrahepatic bile duct ( $>$ Fig. 1 ). We performed single-balloon endoscopy (SBE)-based ERCP but could not identify the hepaticojejunal anastomosis. Therefore, an SBEbased ERCP was performed combined with intravenous ICG $(0.5 \mathrm{mg} / \mathrm{kg})$, which was administered when the SBE was in-

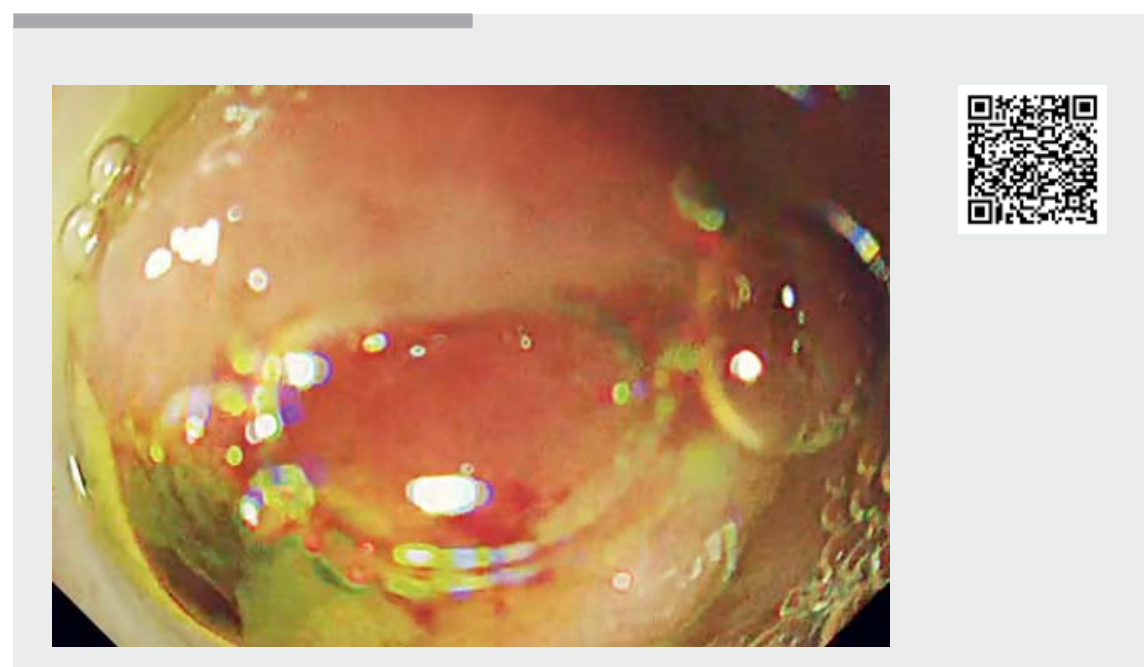

$\checkmark$ Video 1 In a patient with hepaticojejunal anastomotic stenosis, where identification of the anastomosis was difficult, the bile was changed from yellow to green by intravenous injection of indocyanine green, which aided anastomosis identification.

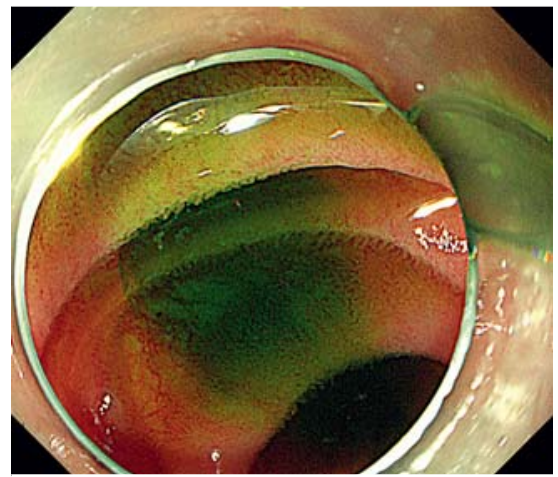

Fig. 2 A color change from yellow to green and an increase in bile retention were observed in the afferent limb approximately 20 minutes after intravenous injection of indocyanine green.

serted into the blind end of the afferent limb ( $\triangleright$ Video 1 ). A color change from yellow to slightly green and an increase in bile retention were observed in the afferent limb approximately 20 minutes after ICG injection ( $>$ Fig.2). This area of colour change was considered to be the anastomosis ( $>$ Fig.3). Bile duct stones were visualized once the ERCP catheter

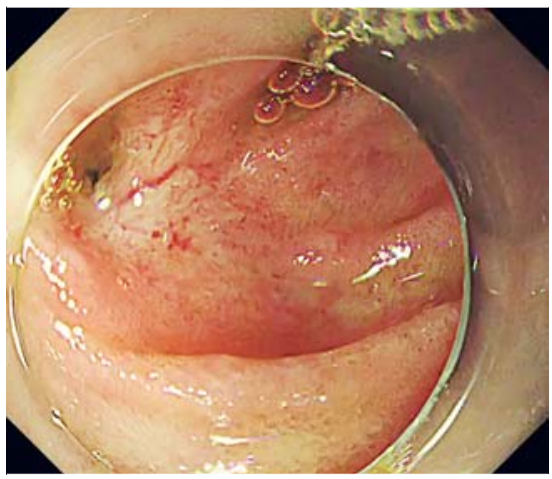

-Fig. 3 The area where the bile had pooled in a deep green hue was identified, and the section was considered to be the anastomosis.

was inserted into the bile duct, and contrast imaging was performed. After dilation of the hepaticojejunostomy with a balloon catheter, a biliary stent was placed.

This is the first reported case of the use of intravenous ICG injection in conjunction with ERCP in reconstructed intestinal tracts. This method can also be 
used to identify the afferent limb in Roux-en-Y gastrojejunostomy cases.

Endoscopy_UCTN_Code_TTT_1AR_2AB

Competing interests

The authors declare that they have no conflict of interest.

The authors

Naohito Uchida, Yuko Bando, Takaaki Mizuo, Sae Hamaya, Toshiaki Nakatsu

Department of Gastroenterology, Saint Martin's Hospital, Sakaide City, Japan
Corresponding author

\section{Naohito Uchida, MD}

Department of Gastroenterology, Saint Martin's Hospital, 1-4-13 Tani-machi,

Sakaide City, Kagawa 762-0033, Japan

Fax: +81-877-460595

n-uchida@sakaide-martinhp.jp

\section{Reference}

[1] Stremmel W, Wojdat R, Groteguth R et al Liver function tests in a clinical comparison. Z Gastroenterol 1992; 30: 784-790
Bibliography

DOI https://doi.org/10.1055/a-1073-7480

Published online: 20.12.2019

Endoscopy 2020; 52: E221-E222

(c) Georg Thieme Verlag KG

Stuttgart · New York

ISSN 0013-726X

\section{ENDOSCOPY E-VIDEOS \\ https://eref.thieme.de/e-videos} 回回 Endoscopy E-Videos is a free

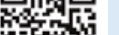

回铻: access online section, reporting on interesting cases and new techniques in gastroenterological endoscopy. All papers include a high quality video and all contributions are freely accessible online.

This section has its own submission website at

https://mc.manuscriptcentral.com/e-videos 